\title{
Analysis of perspective technical solutions for the implementation of integrated heat and cooling systems in a harsh continental climate
}

\author{
Semen Vasilev ${ }^{1}$ \\ ${ }^{1}$ V.P. Larionov Institute of the Physical-Technical Problems of the North of the Siberian Branch of the RAS, Yakutsk, Russia
}

\begin{abstract}
The possibility of introducing the technology of integrated heat and cold supply in a sharply continental climate is considered on the example of a specific district of the city of Yakutsk, the Republic of Sakha (Yakutia), Russia. In this paper is analysed the possibility of district cooling system based on absorption for one district. The characteristics of specific cold consumers are analysed. Various options for district cooling technologies for the conditions of the North are compared. Calculations of cold consumption for buildings of series 1-464A are made. The analysis of the composition of the equipment, technical solutions, reconstruction of buildings, etc. A comparison of the financial and economic efficiency of the chiller-fan coil system and local split systems for a specific consumer is made.
\end{abstract}

\section{Introduction}

Energy development trends are currently leading to the integration of various types of energy into a single complex. A fundamentally new technological paradigm creates a change in the structure of the energy system and a transition from the vertical structure of CHP-networkconsumer to a horizontal structure based on intellectualization and integration [1]. This paper examines the issues of the validity of the development of the Russian energy sector in a new vector of development. One specific element is considered, the introduction of integrated heat and cooling supply systems.

The refrigeration and air conditioning market already has a significant place in the global economy. It exceeds the diamond jewelry market and the wind turbine market. The Economist Intelligence Unit (EIU) estimates annual global sales will grow from 336 million in 2018 to 460 million by 2030 . The amount of sales in monetary terms will be approximately equal to USD 170 billion [2].

The district cooling market has many types and upgrades of equipment. The main technical characteristics of the technology is the type of energy used to create cold. For example, the main criterion in European countries is the use of renewable energy sources that use river energy, geothermal energy, solar, etc. The main drivers for the increase in the share of alternative technologies for district cooling in the European Union are the high price of traditional fuels and the limitation of $\mathrm{CO} 2$ emissions into the atmosphere [3].

Absorption chillers have a significant share in the cooling market. According to research, the presence of waste, cheap heat from CHP operation or waste incineration contributes to the energy efficiency of the system with absorption chillers. Studies show the high efficiency of the integrated heat and cooling system with a confluence of certain factors [4].

The climatic conditions of the city of Yakutsk are of a harsh continental character. Low temperatures in winter contributed to the strong development of the heat supply system. Significant volumes of waste heat and heating networks with high operating temperatures are available. ${ }^{*}$ Corresponding author: vasilievss_ykt $@$,mail.ru
High temperatures in summer create a demand for cold. For example, the number of hot hours (with temperatures above $25^{\circ} \mathrm{C}$ ) in Yakutsk in 2015-2019 is on average 3 times more hot hours in Stockholm, Sweden, where district cooling system has been successfully operating since 1995 [5,6]. For these reasons, this technology has the prerequisites for high energy efficiency, compared to the existing traditional system of combined generation of electricity and heat.

\section{Waste heat availability}

There are 2 thermal power plants in Yakutsk with combined generation of electricity and heat. The consumption of thermal energy in the city of Yakutsk for the winter period is 2.3 million Gcal per year. The length of high-level heat network and heat inputs is 123 kilometers. The length of distribution heat networks 298 kilometers. Equipment composition for 2019:

- Co-generation power plant number 1 - YaGRES. It installed capacity is $368 \mathrm{MW}$, the turbine park includes 12 gas turbine units of Russian production with 8 waste heat boilers PSV-2. Gas turbine units (GTU) include 3 types of turbines: GTE-45, GT-35 and GTG-12V.

- Co-generation power plant number 2 - YaGRES New. It installed capacity of $193.48 \mathrm{MW}$, the turbine park includes 4 gas turbines with LM 6000 PF DF turbines with 3 waste heat boilers KV-GM-116.

The average heat load by plants for the summer period of 2019 is given in Table 1 [7]. The amount of waste heat is calculated using formula (1) as the difference between the total heat supply from the extractions and the total heat load of 2 stations.

$$
\sum Q_{\text {heat }}^{\text {waste }}=\sum Q_{\text {extraction }}^{\text {turbine }}-\sum Q_{\text {load }}^{\text {heat }}
$$

The heat load of the station is calculated by the formula (2) by multiplying the average monthly load by the time of the station operation.

$$
\sum Q_{\text {load }}^{\text {heat }}=q_{\text {heat load }}^{\text {average }} \cdot n
$$


Table 1. Average hourly heat load in summer by stations

\begin{tabular}{|c|c|c|c|}
\hline \multirow{2}{*}{ Power station } & \multicolumn{3}{|c|}{2019 year } \\
\cline { 2 - 4 } & June & July & August \\
\hline YaGRES, Gcal/h & 32 & 37 & 40 \\
\hline YaGRES New, Gcal/h & 17 & 0 & 11 \\
\hline
\end{tabular}

\subsection{Waste heat from YaGRES}

The total heat extraction from gas turbine units is calculated according to the energy characteristics of the turbines Fig. 1 and Fig. 2. Gas turbine units with GTG$12 \mathrm{~V}$ turbines do not produce thermal power.

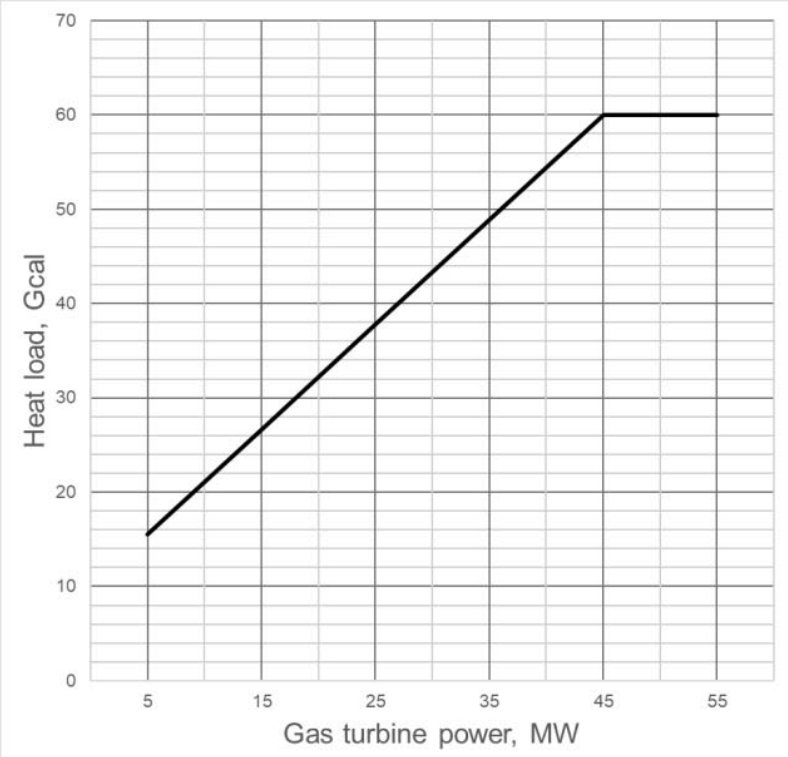

Figure 1. Dependence of heat load on electrical power of GTE45

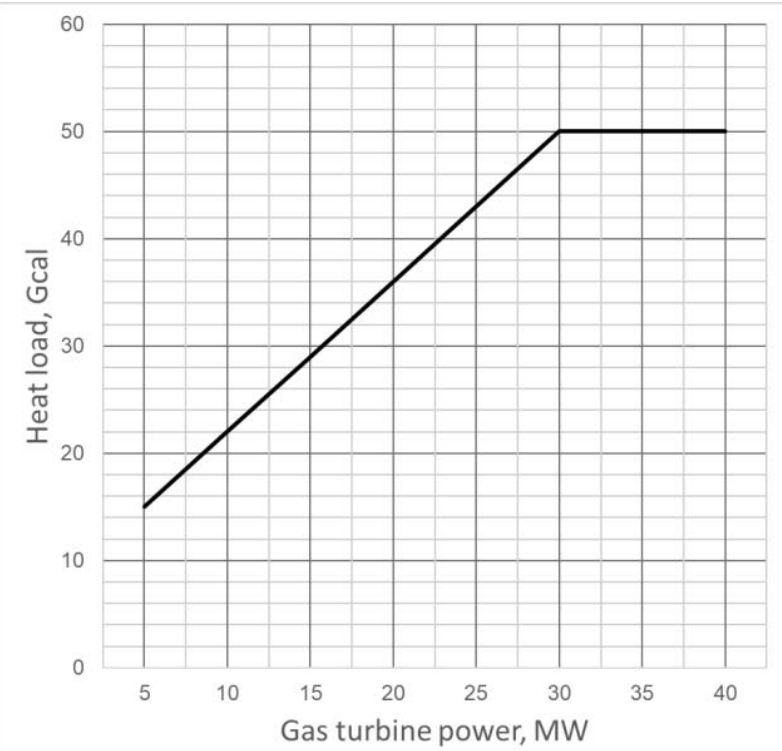

Figure 2. Dependence of heat load on electrical power of GT-35

The calculation of the heat load of each of the gas turbine units was carried out according to the data of the hourly electrical load of the gas turbine units of the station for 3 months: June, July, August.

Next, the total waste heat of the power plant for the month is calculated. The values of the total waste heat from the station were calculated according to formula 1 for June, July, August 2019, the results are given in Table 2 .

\subsection{Waste heat from YaGRES New}

There are no data on the energy characteristics of LM 6000 PF DF turbines at YaGRES New. Waste heat is calculated as the difference between the possible total heat release from the extractions and the heat load of the plant. The possible total supply of heat from the extraction is calculated using the ratio of energy production $Z_{\mathrm{T}}$ in winter time (Table 2). The maximum value of the ratio is 2.62 in December. The total possible supply of heat is calculated according to formula (3), assuming such values of the coefficients in the summer for June, July, August.

$$
\sum Q_{\text {extraction }}^{\text {turbine }}=\sum\left(Z_{\mathrm{T}} \cdot N_{\text {electrical load }}^{\text {summer }}\right)
$$

Table 2. Waste heat in 2019

\begin{tabular}{|l|c|c|c|c|}
\hline \multicolumn{7}{|c|}{ Waste heat, thousand Gcal } \\
\hline № & June & July & August & Sum \\
\hline YaGRES & 235,1 & 207,4 & 230,5 & 673 \\
\hline $\begin{array}{l}\text { YaGRES } \\
\text { New }\end{array}$ & 97,4 & 50,3 & 126,7 & 274,4 \\
\hline Sum total & 332,5 & 257,7 & 357,2 & 947,4 \\
\hline
\end{tabular}

\section{Object of study}

The object of the study is a unified heating system districts 129 and 54 in the centre of the city of Yakutsk. The criteria that were used when choosing the object of research: the presence of significant demand for cold, the ability to connect to a source of thermal energy, the connection of various types of consumers (residential, administrative, commercial, etc.).

Districts 129 and 54 include 40 large potential cold consumers. It includes 22 residential buildings with administrative premises, 4 residential buildings, 14 administrative buildings. Small buildings, garages do not need cold, therefore they are not taken into account in the calculations.

During a visual inspection of districts, it was found that local autonomous split systems cover the cold needs of office buildings by about $70 \%$. And in residential buildings, split systems cover the need for cold by about $10 \%$.

\subsection{Design features of buildings series 1-464A}

As the object of a more detailed study, buildings series 1-464A was selected (Figure 3) [8]. During the construction period of the city, this type of project was the most common. The calculation for this building will be useful for further scaling the model.

The building at Poyarkova 17/1, series $1-464 \mathrm{~A}$ has 4 floors, 4 entrances, 16 apartments are located on one floor. Apartments are divided into 4 types with areas of $31,47.5$, 67.6, $71.7 \mathrm{~m}^{2}$.

Further, possible technical solutions for organizing cold supply in a building of series 1-464A are considered. 


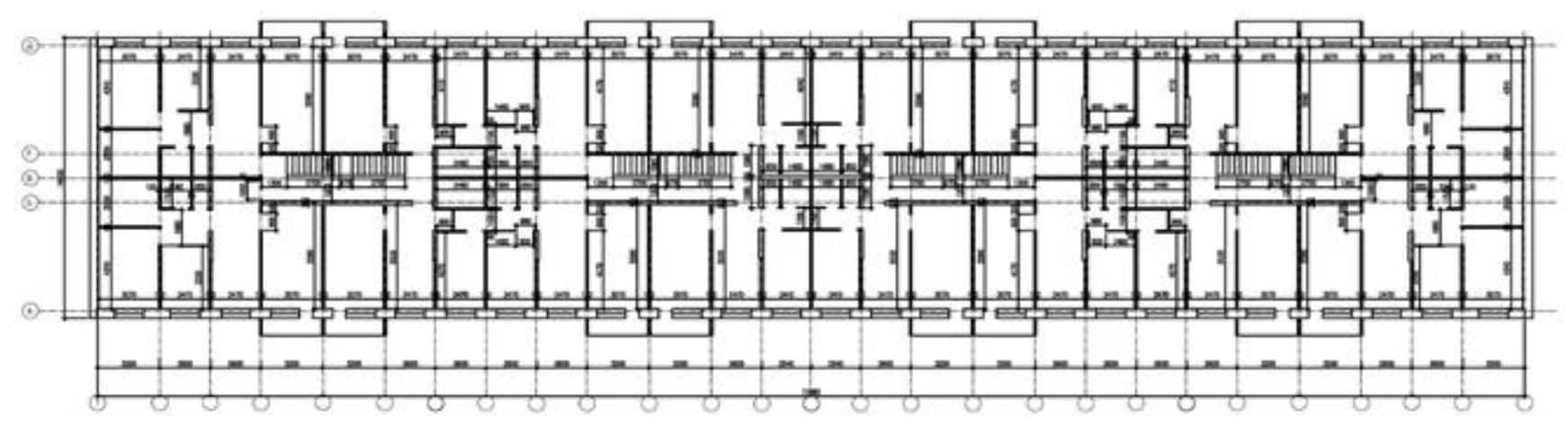

Figure 3. Floor plan of the building series 1-464A

\subsection{Various cooling options in 1-464A buildings}

\subsubsection{Option 1. Using the heating system for cooling}

In the cities of Russia, most of the old buildings of the 50-60s. have a heating system with steel and cast iron radiators, which are not designed for high water consumption. Cooling a house with heating radiators, with a coolant temperature of approximately $8^{\circ} \mathrm{C}$, requires a much higher coolant flow and the outer surface of the radiators. Also, the heating system scheme is mostly made in a single circuit, covering all residential and nonresidential premises, which excludes the possibility of sectioning and correct regulation of the cooling capacity. Another difficulty in implementing such a system is the formation of condensation. Due to the loopback of the entire system and the difference in comfort temperature, intelligent control is required to maintain the desired temperature and avoid condensation. All these and many other factors make this type of cooling impossible.

\subsubsection{Option 2. Local air conditioning systems}

To ensure a comfortable air temperature in residential and public (office) premises $\mathrm{t}=20-23{ }^{\circ} \mathrm{C}, \varphi=40-60 \%$, split-system air conditioners are most widely used [7]. The split system consists of an outdoor unit (compressor, condenser, fan) and an indoor unit (evaporator, fan, filter). The outdoor unit can be installed on the wall of the building, on the roof or on the balcony. Most often in Yakutsk, the external unit is installed on the wall of the building, which worsens the appearance of the building. The indoor unit is designed for cooling, filtering and creating air mobility located directly in the room.

Also, to provide air conditioning (AC), various technical options are possible for local air conditioning systems (ACS): on the basis of on-line air conditioning units, on the basis of on-line fans, on the basis of evaporative air conditioners, etc.

For further calculation, the option with local ACS based on autonomous air conditioners (split system) was selected. The advantages of such a system are easy accessibility to the air conditioning market and no need for additional changes in the building structure. For different types of apartments, local autonomous air conditioners of different capacities were selected, depending on the estimated cold consumption.

\subsubsection{Option 3. Centralized ACS}

Exhaust systems with natural ventilation are installed in buildings of the 1-464A series. They are made in the form of holes in the walls with a radius of $150 \mathrm{~mm}$ and are located in the kitchen and in the toilet. The air in the room is connected to the collection ducts, from there the used air is discharged into the atmosphere through the deflectors [8]. Centralized ACS requires a significant reorganization of the ventilation system: an increase in the diameters of the air ducts, a change in design, etc.

Significant expenses for the reconstruction of the building, complex construction and engineering work make such a system uneconomical.

\subsubsection{Option 4. Chiller and fan coil system}

An absorption chiller can be located in a central chiller station (CCS) near to an existing central heating station (CHS). CCS can be connected to main heating networks with parameters $150-70{ }^{\circ} \mathrm{C}$. The water cooled in the chiller with a temperature of $5-10{ }^{\circ} \mathrm{C}$ enters the user stations of buildings (heat exchangers, automation, control systems, etc.) through external cooling supply networks located parallel to the heating networks. Further, through the building's cooling system, cold water enters the fan coil units.

Such a system requires high capital investments, but has a cheap energy source and a high COP of the chiller.

\section{Calculation of the cooling demand of a typical building}

The cooling demand of a building of series 1-464A is calculated by the graphic-analytical method [9]. The initial data are the orientation of the building, the parameters of the outside and inside air, the number of people, the number of windows, amount of solar radiation. air exchange required to cover heat gain is calculated by the formula (4):

$$
G_{Q}=3.6 \frac{Q_{t}}{\left(I_{i}-I_{o}\right)}
$$

where $I_{i}, I_{o}$ are the specific enthalpies of the indoor and outside air, $\mathrm{kJ} / \mathrm{kg}$, taken according to the I-d diagram; $Q_{t}$ - total heat surpluses, W.

The cold consumption is also determined by I-d diagrams and calculated by the formula (5):

$$
Q_{\text {cooling }}=G_{Q}\left(I_{\mathrm{o}}-I_{\mathrm{i}}\right)
$$


The approximate specific consumption of cold per square meter of a residential building in Yakutsk is calculated using the formula (6) and is equal to 28.8 $\mathrm{W} / \mathrm{m}^{2}$ :

$$
Q_{\text {specific consumption }}=\frac{Q_{\text {cooling }}}{S}
$$

The specific consumption of cold for administrative premises is taken according to specific heat surpluses [10] and is equal to $50 \mathrm{~W} / \mathrm{m}^{2}$.

The calculation of the total demand for cold in districts is calculated using the specific cold consumption per square meter. The operating time of the ACS is equal to the arithmetic mean of the hot hours in Yakutsk with temperatures above $25{ }^{\circ} \mathrm{C}$ from 2015 to 2019 . Air temperature measurement data with an interval of 3 hours were obtained from "Yakutsk meteorological station No. 24959" [5].

Table 3. Cold demand 2019

\begin{tabular}{|l|l|l|l|}
\hline $\begin{array}{l}\text { Area of } \\
\text { premises, } \\
\mathrm{m}^{2}\end{array}$ & $\begin{array}{l}\text { Cooling } \\
\text { capacity, } \\
\mathrm{kW}\end{array}$ & $\begin{array}{l}\text { Number of } \\
\text { hours of } \\
\text { work, hr }\end{array}$ & $\begin{array}{l}\text { Total cooling } \\
\text { demand, } \\
\text { Gcal }\end{array}$ \\
\hline 167677 & 6237,8 & 269 & 1443,1 \\
\hline
\end{tabular}

\section{Initial technical and economic calculation of the district cooling system}

Two options for cooling the buildings of districts are compared: local ACS with individual split systems and a district cooling system with absorption chillers. Cooling options are compared for economic efficiency.

Various cold demand scenarios are used to predict future cooling demand. The scenarios modeled in this article are presented in Table 4.

Table 4. Scenarios of cold consumption

\begin{tabular}{|c|c|c|}
\hline \multirow{2}{*}{ № } & \multicolumn{2}{|c|}{ Cooling system load, \% } \\
\cline { 2 - 3 } & Administrative premises & Living premises \\
\hline Scenario №1 & 100 & 100 \\
\hline Scenario №2 & 100 & 0 \\
\hline Scenario №3 & 50 & 50 \\
\hline Scenario №4 & 100 & 50 \\
\hline Scenario №5 & 100 & 20 \\
\hline
\end{tabular}

The calculation was carried out according to the standard method for evaluating the effectiveness of investment projects [11]. The electricity tariff for the city of Yakutsk was 6.49 rubles / $\mathrm{kWh}$ in 2019. The calculation results are shown in Table 5.

In all scenarios, the payback period of the project exceeds the service life of technical facilities. The reasons for the economic inefficiency lie in the low cold load density, in the limited hours of air conditioning operation and in the relatively cheap cost of electricity.

\section{Conclusions}

The assessment of the introduction of technologies for district cooling system based on absorption chillers shows the technical feasibility of the project.

The project can become cost-effective by increasing cold consumers and considering the systemic effect. The systemic effect appears by increasing the energy efficiency of the entire system. When a large number of air conditioning systems use waste heat as a source of energy instead of electricity, the overall efficiency of the system increases.

Also, this technology may become relevant if other criteria prevail over economic ones. For example, district cooling system helps to reduce $\mathrm{CO}^{2}$ emissions into the atmosphere by reducing the consumption of electrical energy for air conditioning.

In further work, it is planned to develop a methodology for the introduction of integrated heat and cold supply systems adapted to the conditions of Russia. Work is planned in the following areas:

- Development of methodological tools for creating a stochastic model of a cold consumer;

- Hydraulic calculation of the pipeline system;

- Development of plausible scenarios for an integrated heat and cooling system;

- Development of a mathematical model of the heat and cold supply system;

- Analysis of the impact of the introduction of heat and cold supply technology in the power system of Yakutsk.

Such a methodological apparatus can be used when planning the development of large, urbanized cities in the south of Russia, which there is a shortage of cheap fossil fuels.

Table 5. Technical and economic indicators of the district cooling system

\begin{tabular}{|c|c|c|c|c|c|c|}
\hline № & Indicators & Scenario №1 & Scenario №2 & Scenario №3 & Scenario №4 & Scenario №5 \\
\hline 1 & Payback period, year & 67 & - & - & 79 & 100 \\
\hline 2 & Operating costs, thousand RUB & 1797,6 & 1690,8 & 1684,3 & 1744,2 & 1712,2 \\
\hline 3 & Investments, million RUB & 400,2 & 254,6 & 262,1 & 327,4 & 283,7 \\
\hline 4 & Proceeds, thousand RUB & 3020,4 & 1597,1 & 1510,2 & 2308,7 & 1881,7 \\
\hline 5 & $\begin{array}{l}\text { Cooling load, thousand } \\
\mathrm{kWh} / \text { year }\end{array}$ & 1677,9 & 887,2 & 838,9 & 1282,6 & 1045,4 \\
\hline 6 & Cost value, RUB/kWh & 1,071 & 1,906 & 2,008 & 1,360 & 1,638 \\
\hline 7 & Tariff, RUB/kWh & 1,800 & 1,800 & 1,800 & 1,800 & 1,800 \\
\hline 8 & $\begin{array}{l}\text { Profit contribution, thousand } \\
\text { RUB/year }\end{array}$ & 1222,8 & $-93,8$ & $-174,1$ & 564,5 & 169,5 \\
\hline 9 & $\begin{array}{l}\text { Rental fee for } 2.5 \mathrm{~kW} \text { of cold, } \\
\text { RUB/year }\end{array}$ & 1210,5 & 1210,5 & 1210,5 & 1210,5 & 1210,5 \\
\hline 10 & $\begin{array}{l}\text { Split system electricity bill, } \\
\text { RUB \year }\end{array}$ & 1396,6 & 1396,6 & 1396,6 & 1396,6 & 1396,6 \\
\hline
\end{tabular}




\section{References}

1. N.I. Voropai, V.A. Stennikov, E.A. Barakhtenko. Integrated energy systems: challenges, trends, ideology. Studies on Russian Economic Development, 5, pp. 492-499. (2017)

2. The cooling imperative. Forecasting the size and source of future cooling demand. The Economist Intelligence Unit. (2019)

3. Cool conclusions. How to implement district cooling in Europe. Renewable Smart Cooling for Urban Europe (RESCUE). (2015)

4. L. Trygg, S. Amiri. European perspective on absorption cooling in a combined heat and power system - A case study of energy utility and industries in Sweden. Applied Energy, 84, pp. 1319-1337. (2007)

5. S.S. Vasilev, L.M. Baisheva. On the possibility of cooling from a heat power plant on the example of Yakutsk. International technical and economic journal, 6, pp. 7-17. (2019)

6. Best practice examples of District Cooling systems. Renewable Smart Cooling for Urban Europe (RESCUE). (2015)

7. Materials of PJSC "Yakutskenergo"

8. Building plan, series $1-464 \mathrm{a}$

9. T. N. Ilyina, Air conditioning and refrigeration: a tutorial. EBS ASV. (2012)

10. A.G. Sotnikov. Specific air-thermal, heating and cooling loads of typical public premises. AVOK, 5, (2011)

11. P.L. Vilensky, V.N. Livshits, S.A. Smolyak. Evaluation of the efficiency of investment projects. Moscow Publishing house "Delo". (2002) 